\title{
AMS Executive Director Donald E. McClure Retires
}

\author{
Allyn Jackson
}

AMS Executive Director Donald E. McClure will retire in the summer of 2016. For seven and a half years, McClure has provided steady, thoughtful guidance to the AMS, ensuring that the Society continues to thrive in its main role of supporting mathematics and the mathematical community, while also succeeding in its role as a major publisher in the field. McClure's instinctive
McClure is wise and thoughtful, knowledgeable and strategic understanding of how best to align these two roles has been key to his success at the helm of the AMS.

Carla Savage of North Carolina State University has worked closely with McClure since she became Secretary of the AMS in 2013. She praised him as wise and thoughtful, patient and persuasive, knowledgeable and strategic. "He is articulate and respectful and represents the AMS very well to members, volunteers, and external organizations," she said. "He weighs all decisions according to the benefits to mathematics, mathematicians, and the Society. I've never seen him lose sight of these goals."

McClure is professor emeritus of applied mathematics at Brown University. He has a long record of service to the AMS, including hands-on work as a member of the Data Committee and of the Board of Trustees. He also served as AMS Associate Treasurer from 2003 until the time he became AMS Executive Director. This experience meant that he started his position at the AMS with a good deal of understanding of Society operations. He also brought considerable business acumen, having founded, with his Brown colleague Stuart Geman, a successful software development company.

Allyn Jackson is senior writer and deputy editor for the Notices. Her email address is axj@ams.org.

For permission to reprint this article, please contact:

reprint-permission@ams.org.

DOI: http://dx.doi.org/10.1090/noti1406

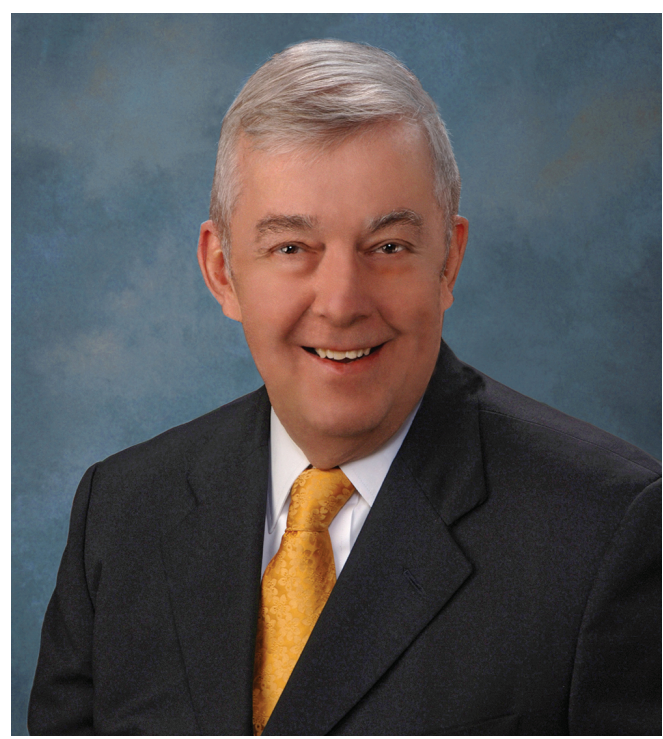

Donald E. McClure

\section{The Best of Times and the Worst of Times}

One could say that McClure joined the AMS staff at the best of times and the worst of times. His predecessor, John H. Ewing, had left the Society in arguably the best possible shape, both financially and in its ability to serve mathematics. But McClure succeeded Ewing in January 2009, in the midst of the worst global economic crisis of recent times. The Society's long-term investment portfolio had declined 30 percent, and the portion of the portfolio that provides funds to support programs and services had dropped 50 percent. As academia struggled to absorb the impact of the crisis, mathematicians faced a bleak employment outlook, budget cuts in their departments, and shrinking library budgets.

In this difficult climate, McClure articulated the main priorities of the AMS to be holding down the cost of 


\section{His calm and}

steady

approach

helped the

Society

weather

tough

economic

times books and journals, helping young mathematicians in the job market, and advocating support for mathematics by the federal government. The AMS enacted these priorities by, for example, freezing journal subscription prices and individual membership dues for a time. Another example is the organization of events at the Joint Mathematics Meetings (JMM) aimed at giving new PhDs information about opportunities outside of academia.

"Don was always thoughtful and deliberate in his decisions and statements, and considered all sides of every issue before making a decision that would impact the AMS," said AMS Treasurer Jane Hawkins of the University of North Carolina. She also noted that his calm and steady approach gained the confidence of the Board of Trustees and helped the Society weather the tough economic times. Over the past seven and a half years, as the economic climate improved, AMS investments have rebounded.

Still, the challenges faced by young mathematicians entering the profession have not abated, and the AMS programs to support them are still very much needed. Having served on the influential AMS Task Force on Employment in the early 1990s, as well as the Committee on the Profession, McClure developed insights into how to support young mathematicians.

As executive director, he oversaw expansion of AMS travel grants for graduate students, to allow them to attend not only the JMM but also AMS sectional meetings. This program now provides a total of 300 grants annually. Also during McClure's tenure, the Mathematics Research Communities program has continued to blossom. This program helps young mathematicians create peer networks that will sustain them as they develop their research careers. A new program established under McClure, in which then-Associate Executive Director Ellen Maycock played a key role, is the AMS Graduate Student Chapters. The program provides a modest amount of funding for activities that support the students' growth as mathematicians. Today there are about 40 Graduate Student Chapters.

Students have a stronger presence in the AMS today than in the past, particularly through their participation in the JMM. Events geared specifically toward students are now standard JMM fare. And the meetings are extremely popular. McClure's tenure coincided with the largest-ever JMM, in Boston in 2012, which drew 7,200 attendees.

\section{Publishing Business Doing Well}

"Day to day, year in and year out, Don has managed the difficult task of harmonizing the business of AMS publishing and MathSciNet ${ }^{\circledR}$ with the needs of the professional society so that it serves the interest of the entire mathematics community," said AMS President Robert Bryant of Duke University. "We are all grateful for his thoughtful advice and unflagging dedication to the Society."

Under McClure's leadership, the AMS publication operation has done well. The Society has continued to publish outstanding books, including books aimed at students at all levels. In McClure's time, the AMS introduced two children's books, both by Richard Schwartz, a colleague of McClure's at Brown University. One of Schwartz's books, Really Big Numbers, published in 2014, received the inaugural Mathical Book Prize of the Mathematical Sciences Research Institute and the Children's Book Council. Another 2014 book published by the AMS, Hilbert's Fifth Problem and Related Topics by Terence Tao, received the PROSE Award (American Publishers Award for Professional and Scholarly Excellence) for the best book published in mathematics that year.

Major strides were made in AMS eBooks while McClure was executive director; among the series now available electronically are Memoirs and Mathematical Surveys and Monographs. AMS journal page output was greatly increased to reduce backlogs, without proportional increases in subscription prices. Also under McClure's leadership, the AMS invested substantial time and effort in retro-digitization, and now all issues of its four primary research journals are available online.

In 2012, McClure developed a proposal for creating "gold" open-access versions of Transactions and Proceedings, so that authors publishing in these journals have an open-access option available. This has allowed the AMS to take a measured step into the rapidly changing world of open-access publishing and have a basis for planning possible future moves in this direction.

The most important publication of the AMS, Mathematical Reviews, had a couple of landmarks during McClure's tenure: Its seventieth and seventy-fifth anniversaries, and its last print issue, which came out at the end of 2012. Math Reviews and its online portal MathSciNet ${ }^{\circledR}$ have kept pace with the enormous growth in the mathematical literature, adding over 80,000 reviews each year. Several new features have been added to MathSciNet ${ }^{\circledR}$, one of the most significant being the use of MathJax ${ }^{\mathrm{TM}}$ to render LTEX on-screen, which has greatly enhanced the ease of use and readability of MathSciNet ${ }^{\circledR}$.

\section{Seeds for the Future}

Two efforts in which McClure was deeply involved, and which will benefit the Society in the years to come, are the establishment of the AMS Development Department and the completion of a strategic planning process. Since it started in 2011, the Development Department has been highly effective in securing resources to support new prizes and activities. Two examples are the Chevalley Prize in Lie Theory, given for the first time this year, and the soon-to-be-established Bertrand Russell Prize, which will recognize the various ways that mathematics research and contributions promote good in the world and further fundamental human values. (McClure credits the great help of David Vogan of the Massachusetts Institute 
of Technology, who served as AMS President during 20132014 , in the creation of these prizes.)

Bryant praised McClure's leadership during the strategic planning activity, which began in 2013. "Don worked tirelessly to keep everyone engaged and moving forward and made sure that all our voices were heard," said Bryant. "This left us with what I think is a very clear picture of the challenges and opportunities that the AMS faces as well as a clear set of

\section{McClure's ability to listen and weigh different points of view counts as one of his strengths} goals and strategies for reaching those goals. The membership of the AMS will reap the benefits of this for many years to come."

One priority emerging from the strategic planning activity was the need to promote diversity in mathematics. Moving quickly in response, this spring the Society established the AMS Department of Education and Diversity. After a national search for the director of this department, Helen G. Grundman of Bryn Mawr College was hired for the position and began working full-time in June.

Running the AMS has not been a one-man show, and McClure's ability to listen and weigh different points of view counts as one of his strengths. Vogan said of McClure, "What was most valuable to me personally was his calm and his perspective. He managed serious disagreements by understanding rather well all the points of view involved, and by never (apparently!) being annoyed."

McClure's good judgment in dealing with people extends to good judgment in hiring. In his time at the AMS, he filled several positions in the senior ranks of AMS staff: Edward Dunne as Executive Editor of Mathematical Reviews, Robert Harington as Associate Executive Director for Publishing, T. Christine Stevens as Associate Executive Director for Meetings and Professional Services, Robin Marek as Director of Development, and Emily Riley as Chief Financial Officer. Savage said that "hiring these amazing people who do so much for the AMS, and do it so well, is probably Don's most important accomplishment." They join long-time AMS senior staff members Sergei Gelfand (Publisher), Thomas Blythe (Chief Information Officer), and Samuel M. Rankin III (Director of the AMS Washington Office) to make a very strong team to head AMS operations.

"Don understands everything about the AMS in wonderful detail, and is an expert at knowing which parts will benefit from attention and which parts just need to be allowed to work," said Vogan. "The AMS has been fortunate to benefit from his intelligence, his wisdom, his kindness, and his humor."

\section{Credits}

Photo of Donald E. McClure courtesy of Marè Studios.

\section{American Mathematical Society}

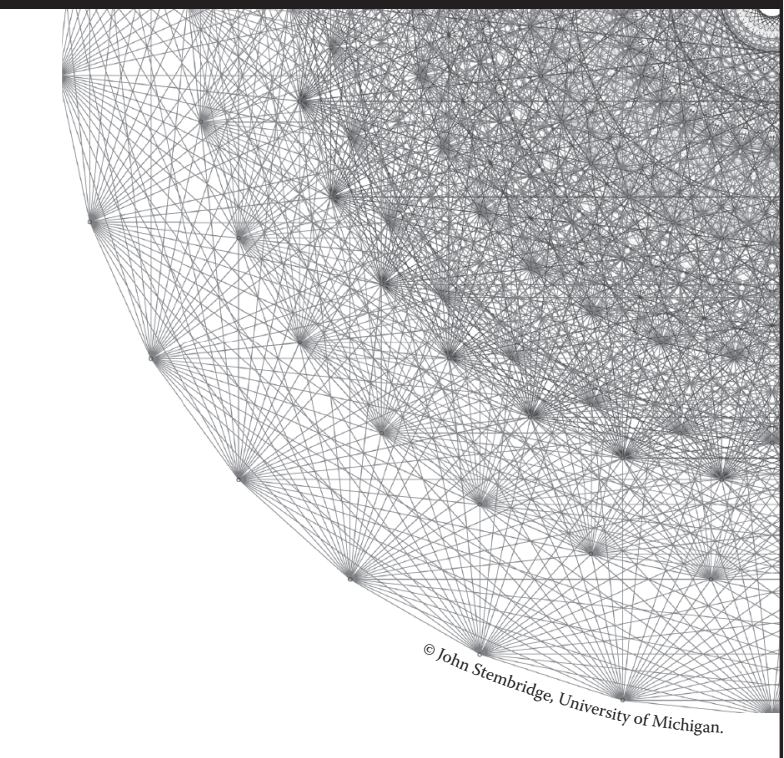

AMERICAN MATHEMATICAL SOCIETY MathSciNet
Mathematical Reviews

www.ams.org/mathscinet

\section{MathSciNet is the most complete and reliable source for your research}

MathSciNet contains information on over 3 million articles and books, with direct links to almost 2 million articles in over 1,800 journals. MathSciNet includes expert reviews, personalizable author profiles, and citation information on articles, books, journals, and authors. Use it to:

- Quickly get up to speed on a new topic

- Look up a researcher's body of work (and find his/her Erdős number!)

- Find an article or book and track its reference list

- Research a math department to prepare for a job interview

- Personalize your author profile

\section{Houblo-Subscribe/Purchase}

Go to www.ams.org/mathsciprice to learn

more about MathSciNet, including information about joining a consortium, subscription rates, and a 30-day free trial. 